\title{
Thermal degradation of banana pseudo-stem filled unplasticized polyvinyl chloride (UPVC) composites
}

\begin{abstract}
The thermal behaviour of banana pseudo-stem (BPS) filled unplastisized polyvinyl chloride (UPVC) composites was studied by means of thermogravimetric analysis. The effects of fiber loading and resin modification on the thermal stability of the composites were evaluated. Resin modifications were carried out by acrylic to improve the fiber-matrix adhesion. From the study, the thermal stability of the composites was found to be higher than that of BPS fiber and the UPVC matrix. It is shown that the incorporation of BPS filler decreases the thermal stability of BPS/UPVC composites for the case of non acrylic. The thermal stability of BPS/UPVC composite with acrylic is found to be higher compared to BPS/UPVC composite without acrylic.
\end{abstract}

Keyword: Carbon fiber reinforced plastics, Gravimetric analysis, Polymers, Polyvinyl chlorides 